\title{
Analysing Media Reactions to Male/Male Dance Partnerships On British Reality TV Shows: Inclusive Masculinity in Strictly Come Dancing and Dancing On Ice
}

\author{
Yen Nee Wong ${ }^{1}\left(\mathbb{D} \cdot\right.$ Vicki Harman $^{1}\left(\mathbb{0} \cdot\right.$ Craig Owen $^{2}(0)$
}

Received: 4 June 2020 / Accepted: 8 June 2021 / Published online: 24 June 2021

() The Author(s) 2021

\begin{abstract}
Strictly Come Dancing and Dancing on Ice are primetime reality television shows that promote partner dancing as a form of leisure in the UK. Both shows have consistently represented partner dancing as a partnership between a man and a woman. However, in 2019 and 2020male/male partnerships were introduced into both shows for the first time. Drawing on media reports that discuss these male/male partnerships, this paper explores how the partnerships were represented and made sense of by mainstream and LGBT + media. Employing thematic discourse analysis, we demonstrate how the male/ male dance partnerships were framed by a complex and contradictory inclusive masculinity discourse. On the one hand, this discourse celebrated the male/male couples as evidence that Britain is a progressive society in which homophobia is in decline. At the same time, the representations largely centred on the male dance couples' bromances while ignoring or silencing discourses of gay love or sex. We show that although the representations can be viewed as a positive step forward, there were also some limitations to the representations which necessitate more critical examination in future research
\end{abstract}

Keywords Male/male partnerships $\cdot$ LGBT $+\cdot$ Strictly Come Dancing $\cdot$ Dancing on Ice · Inclusive Masculinity Theory · Ballroom Dancing · Ice Skating · Partner dancing $\cdot$ Bromance $\cdot$ Intimacies

\section{Introduction}

Strictly Come Dancing (SCD) and Dancing on Ice (DoI) are primetime British television dance shows. Centred around ballroom dancing and figure skating competitions, both shows have traditionally paired mixed sex celebrity and professional

Yen Nee Wong

yennee.wong@ @urrey.ac.uk

1 Department of Sociology, University of Surrey, Guildford, UK

2 Department of Psychology, Anglia Ruskin University, Cambridge, UK 
couples. However, in 2019 and 2020 SCD and DoI introduced two male/male dance partners for the first time: professional dancers Graziano Di Prima and Johannes Radebe on SCD, and professional Matt Evers and celebrity Ian Watkins on DoI. Thus, both shows are connected by the timeliness of their choice of having same-sex dance couples. These watershed moments led to intense media debate about the meaning and appropriateness of male/male couples performing dances based upon traditional heterosexual models of gender and sexuality. In this article, we critically analyse how the mainstream and LGBT + media framed these male/male dance couples. We pay particular attention to how the dancers' gender and sexuality are constructed, and whether the media representations promote the visibility of gay men on TV and disrupt the heteronormativity of partner dancing. Through the above investigation, we address the question of whether the representation of male/male dance partners on SCD and DoI contributes towards progressive inclusivity in the leisure pursuit of partner dancing.

In order to demonstrate why the introduction of male/male dance partners is such a significant milestone, we begin this paper by charting how traditional models of gender and sexuality underpin the two reality television dance shows and the respective dance forms. Following this, we identify how previous research has theorised gender and sexual relations in ballroom dance and figure skating. We then outline our methodology which involved a thematic discourse analysis of online media reports of the two male/male partnerships. Finally, we offer our analysis and conclusion which documents how the media framed the male/male couples within a complex and contradictory inclusive masculinity discourse. We show that although the representations can be viewed as a positive step forward, there were also some limitations to the representations which necessitate further critical examination in future research.

\section{Background to the Television Shows}

Strictly Come Dancing is a long-standing, popular British television (BBC) programme based on Latin and ballroom dancing. First aired in 2004 and running its $18^{\text {th }}$ series in 2020, SCD's format has been translated across the globe to more than 50 countries under the title Dancing with the Stars. Typically broadcast on Saturday evenings with a Sunday night results show to follow, SCD occupies prime time on British television and accumulates a substantial audience of more than 10 million. Supporting SCD is companion programme It Takes Two, broadcast on weeknights to provide audiences with behind the scenes snippets of training sessions and interviews with celebrities, serving to increase viewers' anticipation of the Saturday night show.

SCD works on a format of pairing up approximately 15 celebrities with professional dancers to compete in Ballroom and Latin dances for the glitterball trophy, their performances scored by four judges. SCD viewers are also involved in ensuring their favourite celebrities remain on the show through a phone and online voting 
system. Across its 17 series, celebrities were paired with mixed-sex professionals. This is despite several international versions of SCD (Israel, Italy, Ireland, Australia, United States) having incorporated same-sex couples, and the UK show having had several LGBT + celebrities appearing on the show who have requested a same-sex partnership arrangement, with the judge Craig Revel Horwood voicing his support (Watts, 2015). SCD's persistent adherence to traditional partnerships, despite its inclusion of openly gay celebrities and judges, draws from a long-standing tradition in the UK of viewing ballroom dancing as a dance between a male leader and a female follower (Harman, 2019; Harman \& Wong, 2020).

The second programme which forms part of our analysis, Dancing on Ice (DoI), is also a British television show aired on ITV. It began in 2006, had a short break from 2015 to 2017 , and is now in its $12^{\text {th }}$ series with more than 5 million viewers. The show is based on the partner dancing style of figure skating. Celebrities are paired with professional dancers to figure skate in front of an 'Ice Panel' of judges who are stars or renowned figures in the figure-skating competitive scene. Similar to SCD, DoI motivated various spinoff programmes featuring celebrities outside of the Sunday night series.

DoI draws from the competitive structure of pair skating that requires the partnership to consist of a man and a woman skating together, performing a sequence of tricks, lifts, spins, and various other elements. Couples can also compete in the ice dance category where intricate footwork and closed dance holds are emphasised, with men taking the leader role in the partnership. The heterosexual partnership format and sex-segregated dance moves of this competitive Olympic sport were translated into DoI for the past 11 series, with the most recent $12^{\text {th }}$ series in 2020 breaking away from a solely heterosexual structure, with a male/male partnership between professional figure skater Matt Evers and celebrity Ian Watkins. The following section harnesses masculinity theory to introduce ballroom dancing and figure skating as leisure spaces through which traditional forms of gender and sexuality are negotiated and reproduced.

\section{Theorising Gender and Sexuality in Ballroom Dancing and Figure Skating}

Academic research demonstrates how performances of heterosexuality and conventional gender roles are deeply entrenched in ballroom dancing and figure skating. Scholars note how the movements, music, clothing, and choreography combine to depict romanticized, eroticized, and idealized images of heterosexual courtship and seduction (Adams, 2011; McMains, 2006). The lead-follow dynamic of couple dancing has also received substantial critical attention, with male and female dancers expected to take up traditional, rigid, and mutually exclusive gender roles, regardless of their sexuality (Marion, 2008). As the 'leader', male dancers adopt a position of authority and responsibility, inviting the woman to dance, initiating the dance, supporting their partner, setting the pace, and navigating the couple around the rink or dancefloor. As the 'follower', female dancers must respond attentively to male dancers' lead (Harman, 2019; McMains, 2006), often extending the presentation of the movement and overall 
spectacle through eye-catching dresses and make-up, thus performing hyper-femininity (Marion, 2008; McMains, 2006).

With the material and symbolic representation of conventional, pre-feminist gender dynamics, numerous scholars argue that figure skating and ballroom dancing are sites for the reproduction of hegemonic masculinity, heteronormativity, and unequal gender relations (Adams, 2011; McMains, 2006; Meneau, 2020; Peters, 1992). Hegemonic masculinity is conceptualised as a pattern of practice that legitimates and reproduces unequal gender relations between men and women, and masculinity and femininity (Connell \& Messerschmidt, 2005). This pattern of hegemony is arguably evident in figure skating and ballroom dancing, where unequal gender relations are not only consented to, but actively idealized and choreographed. As such, Adams (2011) argues the polarised gender performances in figure skating reinforce assumptions about natural sex difference and severely limits the embodied expression of skaters. Peters (1992:171) attests "however beautiful, ballroom dance glorifies man and vanquishes woman". Furthermore, Meneau (2020:963) claims that performances of heteronormativity in the Latin American dances "encourage men's entitlement to women's bodies, [and] glorifies and sexualizes abstracted violence [against women]".

In contrast, both Marion (2008) and Leib and Bulman (2007) argue that despite initial appearances, the lead-follow dichotomy should not automatically be interpreted as unequal or patriarchal. Findings from Marion's (2008) ethnographic research into ballroom dancing in the US show that many dancers value both roles and view them as complimentary, interdependent, and indispensable. This point is extended in Picart's (2002) autoethnographic reflections on being a female ballroom dancer, in which she proposes the lead-follow dynamic is "not a crude imposition of power", and the female dancer "is never an unthinking puppet" (p.357). Rather, Picart (2002) experiences the practice of following her partner as an avenue for agency and creative self-expression.

Studies have also harnessed Inclusive Masculinity Theory (IMT) (Anderson, 2009; Anderson \& McCormack, 2018) to explore the inclusion of gay men in couple dance, and how heterosexual male dancers enact complex and dynamic masculinities on and off the dancefloor. IMT emerged from ethnographic work in US and UK universities that identified young, heterosexual men engaging in new patterns of social behaviour - what Anderson (2009) calls 'inclusive masculinities'. These behaviours included socially including gay peers, and engaging in homosocial emotional intimacy, physical tactility, and historically feminized practices. Situated within cultures characterized by declining homophobia, Anderson argued that many men and boys no longer feel the need to distance themselves from homosexuality. In turn, Anderson (2009) theorized that 'orthodox' forms of masculinity (based on homophobia, compulsory heterosexuality, and anti-femininity) had lost their hegemony, and a spectrum of orthodox and inclusive masculinities now co-existed.

Harnessing this approach, Owen and Riley's (2020) ethnographic study of British male university students' engagement in Latin dance provides evidence of dynamic engagement with orthodox and inclusive discourses of masculinity. The authors identify how in the process of learning to move their hips in sensuous and sinuous ways (an activity historically associated with femininity and by association homosexuality in Anglo-American white culture), the young men's performances of masculinity combined and dynamically shifted between orthodox and inclusive 
masculinities. Drawing upon IMT, Richardson (2018) also claims that performancelevel ballroom dancing in the UK is a relatively gay friendly environment with many openly gay participants. At the same time, research suggests that in figure skating and ballroom dancing, concern over male performances of effeminacy persists due to being read as a signifier of homosexuality (Adams, 2011; Richardson, 2018). Thus, gay men are seemingly being accepted into these leisure practices as long as they do not dance in a manner defined as too effeminate. This points to elements of both change and continuity within these leisure spheres.

\subsection{Significance for Leisure Studies}

This research is an important contribution to debates regarding the extent to which there has been a movement towards progressive inclusivity and social justice in leisure. Media representations of figure skating and ballroom dancing are important because they convey messages about whether a certain pastime would be suitable and enjoyable for the audience (Adams, 2011). Aspects of social identity such as gender, sexuality, age and ethnicity, may come to the fore as part of these considerations. Furthermore, beyond participating in the dancing, watching these TV shows is a leisure activity in itself (Morley, 2005), with high viewing numbers, spin-off shows, live tours and merchandise available to purchase (Harman, 2019).

Emerging streams of leisure research draw attention to multiple forms of inequalities in leisure pursuits and the potential for social change through leisure participation. For example, feminist leisure scholars point to the importance of questioning patriarchal structures and power imbalance in leisure opportunities, in particular examining the gendered (Aitchison, 2003; Shaw, 1994; Wearing, 1998) and sexualised (Casey, 2009; Jeffreys, 2003; Jones \& McCarthy, 2010) nature of leisure constraints, and problematising leisure as sites for the reproduction of hegemonic masculinity (Kivel, et al., 2009; Pringle, et al., 2011).

Social justice leisure scholars have identified multiple forms of inequality in leisure participation and advocate for the transformative nature of leisure research to enhance social justice through envisioning the resistive and emancipatory potential of leisure spaces (Parry, et al., 2013; Robinett, 2014). This context illuminates the need for an investigation of whether and how SCD's and DoI's inclusion of same-sex dance partnerships resists the institutionalised heteronormativity underpinning couple dance formats and contributes towards progressive inclusivity. Our analysis of the media coverage regarding the inclusion of male/male dancers on SCD and DoI asks: What discourses are discernible within the representations? To what extent do the representations contribute to progressive inclusivity and what limitations or silences are identifiable?

\section{4. Research Methods}

Using the database Lexis Nexis and the search terms "Strictly Come Dancing samesex" and "Dancing on Ice same-sex", we searched for relevant newspaper articles from October 2019 to March 2020. This was the period the male/male partnerships 
on SCD and DoI were aired. We also conducted a Google search using the same search terms, due to LGBT + media sources not emerging in the Lexis Nexis search. We included LGBT + sources such as Gay Times and Attitude to establish a data set in which divergent representations could emerge.

We initially collected 293 articles. We sifted through the articles and removed duplications. These included articles that recapped previous reports and/or offered extensive quotations of materials already covered. When similar articles across multiple media sources reported on the same incident, we retained the primary source and removed other sources that provided no further insights. Sources from local newspapers were also removed to prioritise reports from news sources with national circulation. Furthermore, in order to broaden the representativeness of media sources, an equal selection of tabloid and broadsheet were sought. We ultimately winnowed the data set to 48 media reports, 27 focusing on SCD and 21 on DoI. The media reports included headlines, the main written story, and any accompanying images.

Our analysis was underpinned by post-structuralist assumptions that included a focus on the role of discourses and media representations in constructing reality. Discourses are relatively coherent forms of sense-making that produce certain understandings of, for example, male/male dance couples. The media play a central role in (re)producing discourses, through their choice of what stories, events, and perspectives to represent, and how they frame them through language and imagery. The male/male dance couples can thus be understood as constituted through discourses, in other words, audiences cannot understand them without drawing on discourse (Owen \& Riley, 2020). Discourses also produce 'subject positions', a term used to describe the types of roles, person or characters audiences can connect with (Davies \& Harré, 1990). The subject positions made available to audiences constrain or legitimise particular thoughts, feelings, actions and forms of talk.

We undertook a thematic discourse analysis of the media reports to identify how they collectively produced ways of speaking about and representing the male/male dance partners. We integrated Braun and Clarke's (2006) approach to thematic analysis with Willig's (2013) approach to Foucauldian discourse analysis. The first author read, re-read and coded the entire data set, and identified the main 'objects of discourse': the common ways in which the male/male dance couples were discussed and visually represented. The first and second author then identified codes that coalesced to form themes, and discussed the competing and potentially contradictory ways in which the male/male dance partners and the audience were represented in relation to each theme. The whole research team then explored the extent to which the findings connected with hegemonic masculinity theory (Connell \& Messerschmidt, 2005), inclusive masculinity theory (Anderson, 2009; Anderson \& McCormack, 2018), and post-structrualist informed inclusive masculinity theory (Owen \& Riley, 2020). We also discussed the potential consequences of the representations in terms of homophobia, sexism, effeminophobia, and the visibility and normalisation of male/male dance partnerships and LGBT + representation. Finally, when identifying evocative quotes and images to illustrate the themes, and when writing up the paper, we engaged in an iterative process of re-analysis and debate about the appropriateness of different theoretical lenses. 


\section{Analysis}

In the analysis that follows, we show how the media reports represented the male/ male dance partnerships on SCD and DoI through a complex and contradictory inclusive masculinity discourse (Owen \& Riley, 2020). The discourse consisted of two key themes:

1. 'We're moving in tune with progressive society'. This theme focuses on how the media reports constructed Britain as a progressive and inclusive society, and positioned viewers who complained about the male/male dance partners as a homophobic minority.

2. 'Celebrating bromance, decentring gay love and sex'. This theme explores how the media reports selectively represented the male/male dance couples' embodied interactions, celebrating their friendships as bromances, while simultaneously de-centring the dance performances as romantic or (homo)sexual.

\section{1 'We're Moving in Tune with Progressive Society'}

Commenting on the inclusion of male/male partnerships in SCD and DoI, the majority of articles presented the inclusion as reflective of reduced levels of cultural homophobia and increased support for the LGBT + community, both on the show and in wider British society. The media reports consistently represented SCD and DoI as inclusive programmes. Quotes from supportive stakeholders including judges, producers, dance professionals, contestants, and audiences were deployed to evidence the eagerness to embrace the addition of same-sex dance partnerships. For example, the following claim from the SCD producers was presented in numerous mainstream and LGBT + newspaper articles: "Strictly Come Dancing is an inclusive show and is proud to have been able to facilitate the dance between Johannes and Graziano during the professionals' dance" (Wynne, 2019; Ingate, 2020; O'Connor, 2020; Frodsham, 2019; Wakefield, 2020; Davies, 2019; Dean, 2019; Saunders, 2019; Kelleher, 2020). The SCD producers were also reported in the Daily Mail, Independent, BBC News and Guardian to be "completely open to the prospect of including same-sex pairings between our celebrities and professional dancers in the future" (Davies, 2019; McGregor, 2020; O'Connor, 2020; Rusk, 2020).

The life story of Johannes Radebe, one of the gay-identifying SCD dance professionals who danced in the male/male partnership, was mobilised by journalists in The Sun, Telegraph and Independent to argue that male/male dance partnerships played a significant role in increasing the acceptance of LGBT + people on the programme and increasing wider LGBT + visibility (McPhee, 2019; Swain, 2019; Young, 2019). Journalists offered accounts of Radebe's experience of homophobic bullying while growing up in South Africa. The reports noted how he felt a sense of liberation and acceptance within a progressive and tolerant British society, which he claims facilitated his dancing in the male/male partnership. In turn, Ian Watkins, 
the gay identifying male celebrity who formed part of the male/male couple from DoI, was quoted in the Daily Mail as describing same-sex dance partnerships on the show as "a natural progression", and indicative of wider changes in British society wherein "same-sex relationships are accepted in wider society and visible in competitive sport" (Johnston, 2020). In The Mirror, Rainbird (2019) also proposed an explicit connection between male/male dance partnerships and the wider LGBT + community, with reports of Ian describing his figure skating performances as "flying a massive LGBTQ flag".

Viewing these initial findings through the lens of inclusive masculinity theory helps us make sense of the media framing. As such, IMT theory argues that in cultures of declining cultural homophobia, gay men are increasingly included in a range of social settings (Anderson, 2009). This has been documented in a growing body of IMT research exploring the generally positive discourse surrounding media reporting of professional male sports stars who have recently come out as gay (Cleland, 2014). The media representations of the male/male dance couples seemingly echo these findings.

That said, it is important to remember that Anderson (2009) argued decreasing homophobia is an uneven social process. This was evidenced in the media reports with journalists often noting that some viewers had raised concerns and lodged complaints against the inclusion of the male/male dance couples on SCD and DoI. For example, in The Guardian, Davies (2019) reported 189 complaints were made through the BBC's official complaints process, with viewers expressing it was "offensive to feature two men dancing as a pair" and that viewers would stop watching the programme if the $\mathrm{BBC}$ continued to showcase same-sex pairings. In response, language used in both the mainstream and LGBT + media helped to position protesters as a backward and homophobic minority. Examples of such terms included "haters" (Heap, 2020; Kyriazis, 2020), "homophobic", "homophobe" (Bennett, 2020; Kyriazis, 2020; Nicholson, 2020; Saunders, 2019), "bigots" (Milton, 2020), "stuck in the dark ages" (Bennett, 2020) and "silly" (Heap, 2020; Kelleher, 2020).

Several of the articles contextualised the number of viewer complaints with the total viewership of SCD and DoI. For example, a journalist writing for the Guardian framed the complaints as being from a small minority of viewers: "300 of the 9.4 million who watched last week [which is]...0.003\% of viewers" (Nicholson, 2020). They also compared the number of complaints for these shows against complaint rates for other programmes. For example, in the Pink News, Wakefield (2019) compared the complaints against those for another television show-Countryfile Autumn Diaries—which accumulated 135 complaints over a "bias against motorbikes in the Lake District". Across both mainstream and LGBT + media sources, the complaints against the male/male couples were also positioned against a backdrop of "massive love", "support" and "praise" for the dancers, with fans' comments on social media used to represent an overwhelmingly supportive audience (Armstrong, 2019; Davies, 2019; Frodsham, 2019; Heap, 2020; Kelleher, 2020; Masters, 2020; Milton, 2020; Pike, 2019; Saunders, 2019).

The voices of distinguished LGBT + figures in SCD and DoI were also mobilised in the media reports to downplay the audience complaints. For example, 
articles in The Evening Standard and Telegraph (Frodsham, 2019; Telegraph, 2019) relayed the sentiments of Bruno Tonioli, the gay-identifying SCD judge:

"It's hard to believe after such progress in society and many other topics going on that over 200 people felt so upset they complained when 2 men danced with each other ... I just don't know what to say."

In this excerpt, the construction of Britain as a progressive society works to make the audience complaints against the male/male couple seem ludicrous, petty and out of date.

The final rhetorical strategy the journalists employed to support the inclusion of male/male dance couples was to argue that these shows were already considerably 'gay', and so provided an obvious site for the explicit inclusion of samesex dance partners and gay male dancers. For example, in an article in The Sun (McPhee, 2019), Michelle Visage, a female celebrity dancer on SCD, was quoted as saying, "Strictly is already very gay - just look at it, all the tight trousers and glitter. There's all these guys that step out in rhinestone outfits". Here activities stereotypically associated with femininity, such as using clothes and accessories to draw attention to the body, are interpreted as gay when used by men and are in turn seen as evidence for dance to be a safe space for the inclusion of gay men. Similarly, in The Guardian, Nicholson (2020) drew on the campness of SCD to mock the double standards of dissenters against same-sex dance partnerships:

"I can laugh about a small proportion of the audience feeling confused as they navigate the campness of Strictly while also feeling something funny about two men dancing closely (maybe it's homophobia, but maybe it's just desire)".

Taken together, this theme demonstrates how the various voices of support for male/male dance couples and the challenges to audience complaints were framed within an inclusive masculinity discourse. As such, the media reports constructed British society as progressive and generally supportive of the male/male dance couples and LGBT + visibility more generally. In turn, audiences who submitted complaints were positioned as a homophobic minority and their voices treated with contempt as a relic from the past.

\subsection{Celebrating Bromance, Decentring Gay Love and Sex}

In this section, we illustrate the ways in which media representations of dancers in male/male dance partnerships draw boundaries across three forms of intimacies to construct the discourse of a bromance between the dancers. According to Anderson (2014a, b, p. 123), bromance constitutes the 'love affair' between two heterosexual men, characterised by emotional intimacy and physical affection without the sexual attraction, made possible in times of decreasing cultural homophobia. The concept of bromance has since been mobilised and investigated by scholars, who consider bromance to be a new form of friendship between heterosexual men, characterised by an emotionally intense bond (DeAngelis, 2014; Robinson, et.al., 2017). Intimacy 
here connects with three aspects: physical, emotional and sexual, with the sharing of the first two aspects and the exclusion of the sexual being a prerequisite for the characterisation of close friendships between men as bromances (Anderson, 2014a, b; Davies, 2014; DeAngelis, 2014; Robinson, et al., 2017).

In a range of media reports, including the Evening Standard, Guardian, Mirror, Daily Mail and Pink News, the relationship between the male/male dancers in SCD was repeatedly presented as a bromance (Collie, 2019; Davies, 2019; Dean, 2019; Frodsham, 2019; Kelleher, 2020; Saunders, 2019). Reports typically presented Johannes Radebe's personal account of his relational connection to Graziano di Prima, where Radebe explicitly constructed it as a bromance:

"There's bromance galore between us, but there were no male and female roles, just free movement. It was beautiful, classy and elegant".

The bromance discourse was further reproduced by reports which emphasised di Prima's heterosexuality. More than half of the articles on SCD positioned Radebe's closeness to di Prima within the context of his being di Prima's "best man when he gets married to fellow Burn the Floor dancer Giada Lini" (Swain, 2019). Similarly in DoI, a bromance relationship was portrayed between the male couple Ian Watkins and Matt Evers. In the Daily Express, professional skater Matt "confirmed they were "really good friends"", adding that "[w]e actually both went on dates last week with guys we met on Tinder, so I'm still looking for my Prince Charming." (Earnshaw, 2020). Matt Evers' use of "really good" to describe the friendship suggests some intensity and closeness akin to a bromantic relationship. With both dancers in the partnership being openly gay, a declaration of their availability for love outside the dance partnership, coupled with Evers' statement that he "ha[s]n't looked at him [Ian] as a potential partner outside the rink" (Earnshaw, 2020), appears to reassure the audience that intimacy in their performance was displayed in the physical and emotional aspects, since sexual desire was absent. In the Daily Mail, Johnston (2020) reports that the couple "are keen to stress that their routines won't be raunchy", directly quoting Matt Evers' description that the performance "is going to be more buddy-buddy". Matt's use of words such as "raunchy" and "buddy-buddy" in the above article makes it clear to readers that sexual desire will not be displayed in their performance, that a "buddy" style intimacy characteristic of bromance is sought.

Photographs accompanying the media reports also reflected the bromance theme across both shows. For example, for DoI, a significant number of media sources such as the Mirror (Pike, 2019; Rainbird, 2019), Telegraph (Power, 2020), Daily Mail (Johnston, 2020; Rusk, 2020), Daily Express (Earnshaw, 2020; Kyriazis, 2020; Williams, 2020), Daily Star (Bird, 2019), Metro (Miller, 2019), Pink News (Milton, 2020) and Gay Times (Bennett, 2020) used pictures at the top half of the articles which depicted the couple displaying some physical intimacy in the form of holding each other's hands and skating side by side. Emotional intimacy seemed to be absent as the couple were not facing each other, but rather gazing out at the audience. Sexual intimacy also appeared absent in these photographs as male dancers' engagement was with the audience rather than each other. Such depictions of the relational dynamics between male couples in both DoI and SCD appear rather different from the visual portrayals of heterosexual 
pairings which includes more emotional connection in terms of eye contact, affective display and touch. Apart from displaying greater forms and intensity of intimacy, heterosexual couples also tend to be portrayed simultaneously expressing more than one type of intimacy, such as sexual desire through physical intimacy.

The exclusion of sexual intimacy is further illustrated in DoI professional Matt Evers' interview with the Daily Star (Bird, 2019) and Mirror (Pike, 2019), where Matt Evers was described in Pike's (2019) article as having the intention to "gauge audience reaction before making the routines too intimate". In both these articles, Evers was quoted in his discussion of the performance as "trying to make it [male/male partnerships] normal", such that "if the audience and fans embrace it, we're going to push it a bit more. If they don't, we'll strip it back and it'll be more of a friendship". Although it is not possible to fully know what Matt Evers meant by 'push it a bit more', we can infer this would be likely to mean a more intimate and sexualised performance. In these media reports, there seems to be a suggestion that stripping away sexual intimacy would make the male coupling more acceptable to the public, and that a bromance theme should first be mobilised to test the waters and "normalise" male/male dance partnerships. The notion of "stripping it back" to a "friendship" also points to the starting point being the display of a relationship more intense than that of a friendship, perhaps akin to a bromance where physical and emotional intimacy is involved. This testing the water mentality is made clearer in Evans' (2020) report for Metro, written after the couple's first performance which received significant support. In this article, the pair are presented as "ready to take things a step up", which involved them "sp[eaking] to producers to see if we can make the routines a little steamier" and "take it up a notch and add some romance". This highlights the possibility of displaying sexual attraction through the dance, albeit suggesting that show producers have control over the intimacy level they display on the dancefloor and how their relationship could consequently be represented on the media.

\section{Discussion}

\subsection{Affordances of Inclusive Masculinity Discourse}

An inclusive masculinity discourse is reflected in most of the newspaper reporting of the introduction of male-male dancers on these mainstream programmes. This emphasised that reduced homophobia in the British society opened up space for more inclusive representation on reality TV shows. By deeming the public ready for a change, an inclusive masculinity discourse locates the audience and wider public as the driving force for changes in media representation, and the ones setting the standards for acceptability. This climate of wider public acceptance was leveraged upon by SCD and DoI to justify a disruption of the traditional show format which had been running for more than a decade. Through the introduction of male/ male dance partnerships in the 2019/2020 seasons, both SCD and DoI rebranded themselves as supporters of inclusivity and diversity within a progressive society. This initial shift in programme structure contributed towards a stepped increase in inclusion and diversity in the representation of partner dancing. Through SCD's and 
Dol's pioneering moves of including male couples, same-sex dance partnerships came to be a more expected part of the shows. Arguably this helped to pave the way for later same-sex dance partnerships between professionals and celebrities including a female-female partnership between Katya Jones and Nicola Adams in SCD (BBC, 2020).

Framed within an inclusive masculinity discourse, the male/male dance partnerships were not only heralded as a sign of increased visibility of gay men on primetime television, but of the LGBT + community more generally. Positioned as ambassadors of the LGBT + community, the increasing visibility of gay same-sex dancers was equated with increased acceptance of LGBT + communities as a whole. Media discussion of male dancers' past experiences of homophobia increases public awareness of the negative impacts of homophobia on the lives of LGBT + individuals. In so doing, progressiveness and increased acceptance of the LGBT + community is reiterated and reinforced through inclusive media representation, in this case through SCD and DOI's incorporation of male/male dance partnerships into their programmes.

\subsection{Limitations of the Inclusive Masculinity Discourse}

Critiquing the positive discourse of IMT, O'Neill (2015) argues “it is necessary to challenge discourses of easy optimism and instead pursue more complicated narratives that recognize change alongside continuity, permutation, and retrenchment" (p.116). Whilst British society may have progressed to a context where homophobic speech and violence are less evident or tolerated in the public sphere, one ought not assume that such a change signals the achievement of an inclusive society free from all forms of gender and sexual discrimination. The framing of dancers in male/male dance partnerships within an inclusive masculinity discourse might overemphasise progressiveness in relation to LGBT + inclusivity, as a result foreclosing further discussions on how greater inclusivity of diverse genders and sexualities may be achieved through media representation of same-sex partner dancing.

Our analysis demonstrated that mobilising a bromance discourse desexualised same-sex dancing. This is echoed by Chen (2012) who critiques bromance for its "bro" element which reinforces heteronormativity and homophobia in its regulation of male intimacies and denial of gay sexual desire between men. Not focusing on gay romantic love and sexuality within media representations of male couples arguably contributes to the persistence of selective homophobia in partner dancing, echoing notions of Miraftab's (2004) "invited spaces" for leisure participation. Taking a critical perspective, one might thus suggest that bromance appropriates queer elements and silences gay love, and that its discursive mobilisation in media representation of male/male dance partnerships serves to maintain rather than challenge the traditional heterosexist format of partner dancing.

On the other hand, some might argue that dancers do not necessarily have to display private sexuality or identity through their dance and ought instead to be performing as professionals or individuals taking part in a show (Nakamura \& Matsuo, 
2003). We agree that dancers do not necessarily have to express their lived experiences of familial relations and personal identities in their public performances. However, we argue that the history of partner dances such as ballroom dancing and figure skating is distinct because gender, sexuality and connection between the two dancers is integral to the dance. Partner dancing in its traditional form is built upon a fantasy of romance (Harman, 2019), a leisure realm where physical, emotional and sexual intimacies between dance partners is openly displayed (Ericksen, 2011). Within such a context, and especially in romantic dances such as the Rumba or Waltz, physical and emotional intimacy would likely be interpreted by audiences as sexual desire. A bromance discourse cushions the potential disruptiveness of male/ male partnerships in relation to the traditional dance format through the de-centring of sexual intimacy, love and romance, which are centrepieces of the mainstream representations of these pastimes.

\section{Conclusion}

This paper has argued that SCD and DoI offer interesting case studies of two British television shows that include same sex partnerships at the same moment in time. Although these developments were largely celebrated in the newspaper articles, our analysis also noted how an inclusive masculinity discourse foregrounded bromance, yet revealed omissions (sexual and romantic intimacy between men) which have historically been represented within mixed sex partnerships. This analysis contributes to IMT by highlighting where the boundaries of inclusive masculinity are and how they are mobilised. The commentary on the TV shows discussed illuminate that there are still some forms of gender/sexual inclusion not yet being embraced with media deployment of an IM discourse. As such, the findings provide an indication of where IMT scholars could critically reflect more on the extent of 'inclusion' implied under the guise of inclusive masculinity. In terms of future research, there is potential for inclusive masculinity and dance scholars to extend bromance beyond the masculine realm, through examining the possibilities for bromance to be embodied by SCD's first female pairing in the 2020 season. Future scholarship could also utilise a qualitative approach in order to explore LGBT + perspectives on current representations and the extent to which this might encourage or preclude people from watching the shows and taking up these pastimes within mainstream and LGBT + focused leisure spaces. Finally, there is also scope to examine the perspectives of non-LGBT + audience on the media representation of male/male dance partnerships as the analysis suggests that assumptions around this may be limiting the representations of these leisure spheres on our screens.

Funding The authors received no specific funding for this work.

Data Availability Not applicable.

Code Availability Not applicable. 


\section{Declarations}

Conflicts of interest/Competing interests No potential conflict of interest was reported by the authors.

Ethics approval The work did not require human or animal participants.

Consent to participate Not applicable.

Consent for publication Not applicable.

Open Access This article is licensed under a Creative Commons Attribution 4.0 International License, which permits use, sharing, adaptation, distribution and reproduction in any medium or format, as long as you give appropriate credit to the original author(s) and the source, provide a link to the Creative Commons licence, and indicate if changes were made. The images or other third party material in this article are included in the article's Creative Commons licence, unless indicated otherwise in a credit line to the material. If material is not included in the article's Creative Commons licence and your intended use is not permitted by statutory regulation or exceeds the permitted use, you will need to obtain permission directly from the copyright holder. To view a copy of this licence, visit http://creativecommons.org/licen ses/by/4.0/.

\section{References}

Adams, M. L. (2011). Artistic impressions: Figure skating, masculinity, and the limits of sport. University of Toronto Press.

Aitchison, C. C. (2003). Gender and leisure: Social and cultural perspectives. Routledge.

Anderson, E. (2009). Inclusive masculinity: The changing nature of masculinities. Routledge.

Anderson, E. (2014a). 21st century jocks: Sporting men and contemporary heterosexuality. Palgrave.

Anderson, Z. (2014b). Potential ban on same-sex dance partners at BDC competitions. Dancing Times, 11 July. [Online] Available at: http://www.dancing-times.co.uk/bdc_same_sex_ban/. Accessed 20 March 2020.

Anderson, E., \& McCormack, M. (2018). Inclusive masculinity theory: Overview, reflection and refinement. Journal of Gender Studies, 27(5), 547-561.

Armstrong, L. (2019). KEEP DANCING! Bruce Forsyth's widow says he would have loved sexed-up Strictly and same-sex dancers. [Online] Available at: https://www.thesun.co.uk/tvandshowbiz/ 10506430/bruce-forsyth-widow-strictly-same-sex-dancers/. Accessed 22 March 2020.

BBC (2020). Strictly Come Dancing launch sees Nicola Adams and Katya Jones paired. https://www.bbc. co.uk/news/entertainment-arts-54587591. Accessed 10 March 2021.

Bennett, S. (2020). Dancing on Ice's first same-sex routine receives just 16 complaints. [Online] Available at: https://www.gaytimes.co.uk/culture/131229/dancing-on-ices-first-same-sex-routine-recei ves-just-16-complaints/. Accessed 22 March 2020.

Bird, D. (2019). Dancing On Ice fans in tears as Ian H Watkins partnered in first same-sex couple. [Online] Available at: https://www.dailystar.co.uk/tv/dancing-ice-fans-tears-ian-21150041. Accessed 22 March 2020.

Braun, V., \& Clarke, V. (2006). Using thematic analysis in psychology. Qualitative Research in Psychology, 3(2), 77-101.

Casey, M. (2009). Tourist gay(ze) or transnational sex: Australian gay men's holiday desires. Leisure Studies, 28(2), 157-172.

Chen, E. J. (2012). Caught in a bad bromance. Texas Journal of Women and the Law, 21(2), 241-266.

Cleland, J. (2014). Association football and the representation of homosexuality by the print media: A case study of Anton Hysén. Journal of Homosexuality, 61(9), 1269-1287.

Collie, J. (2019). Strictly Come Dancing star Johannes Radebe says show's first all-male dance left him feeling liberated and accepted. [Online] Available at: https://www.standard.co.uk/stayingin/stric 
tly-come-dancing-star-johannes-radebe-says-shows-first-allmale-dance-left-him-feeling-liberateda4277581.html. Accessed 22 March 2020.

Connell, R., \& Messerschmidt, J. W. (2005). Hegemonic masculinity: Rethinking the concept. Gender and Society, 19, 829-859.

Davies, N. (2014). I love you, hombre: Y tu mamá también as border-crossing bromance. In M. DeAngelis (Ed.), Reading the bromance: Homosocial relationships in film and television (pp. 109-138). Wayne State University Press.

Davies, H. J. (2019). Strictly Come Dancing's first same-sex routine sparks almost 200 complaints. [Online] Available at: https://www.theguardian.com/tv-and-radio/2019/nov/21/strictly-come-danci ngs-first-same-sex-routine-sparks-complaints. Accessed 22 March 2020.

Davies, B., \& Harré, R. (1990). Positioning: The discursive production of selves. Journal for the Theory of Social Behaviour, 20, 43-63.

Dean, C. (2019). Strictly Come Dancing's Graziano Di Prima sends temperatures soaring as he poses shirtless in a series of steamy snaps for new calendar. [Online] Available at: https://www.dailymail. co.uk/tvshowbiz/article-7739675/Graziano-Di-Prima-sends-temperatures-soaring-poses-shirtless. html. Accessed 22 March 2020.

DeAngelis, M. (2014). Reading the bromance: Homosocial relationships in film and television. Wayne State University.

Earnshaw, J. (2020). Matt Evers talks romance with Dancing on Ice partner Ian 'H' Watkins in 'curse' admission. [Online] Available at: https://www.express.co.uk/celebrity-news/1232915/Matt-Evers-DancingOn-Ice-partner-Ian-H-Watkins-romance-curse-news-latest-update. Accessed 24 March 2020.

Ericksen, J. A. (2011). Dance with me. Ballroom dancing and the promise of instant intimacy. New York University Press.

Evans, M. (2020). Dancing On Ice's Matt Evers doesn't rule out romance with Ian 'H' Watkins after laughing off Ofcom complaints over same-sex coupling. [Online] Available at: https://metro.co.uk/ 2020/01/12/dancing-ices-matt-evers-doesnt-rule-romance-ian-h-watkins-laughing-off-ofcom-compl aints-sex-coupling-12046725/. Accessed 22 March 2020.

Frodsham, I. (2019). Strictly Come Dancing judge Bruno Tonioli hits back at complaints over same-sex dance. [Online] Available at: https://www.standard.co.uk/showbiz/celebrity-news/strictly-comedancing-bruno-toniolli-same-sex-dance-ofcom-a4292926.html. Accessed 22 March 2020.

Hall, M. (2015). Metrosexual masculinities. Palgrave Macmillan.

Harman, V. (2013). All the girls get to look pretty: Ballroom and Latin American dancing as leisure. In: Mapping leisure across borders. (pp. 164-176). Cambridge Scholars.

Harman, V. (2019). The sexual politics of ballroom dancing. Palgrave.

Harman, V., \& Wong, Y. N. (2020). Same-sex pairings on Strictly: LGBT+ identity and leisure participation in ballroom dancing. In S. Kono, A. Beniwal, P. Baweja, \& K. Spracklen (Eds.), Positive sociology of leisure. (pp. 159-174). Palgrave Macmillan.

Heap, T. (2020). Strictly's Graziano shuts down same-sex dance complaints. [Online] Available at: https://attitude.co.uk/article/dance-is-love-thats-it-strictlys-graziano-di-prima-shuts-down-samesex-dance-complaints/22533/. Accessed 22 March 2020.

Ingate, K. (2020). Bruno Tonioli: 'Have to be careful' Strictly judge warns BBC bosses over same-sex couples. [Online] Available at: https://www.express.co.uk/celebrity-news/1248593/Bruno-TonioliStrictly-Come-Dancing-2020-same-sex-couple-warning-Dancing-on-Ice-news. Accessed 22 March 2020.

Jeffreys, S. (2003). Sex tourism: Do women do it too? Leisure Studies, 22, 223-238.

Johnston, J. (2020). Dancing on Ice introduces its first same-sex couple this year. Here, Ian 'H' Watkins tells why he's delighted they beat Strictly to it - while three of his rivals reveal the boost (and the bruises) the show's given them. [Online] Available at: https://www.dailymail.co.uk/femail/article7844741/Dancing-Ice-introduces-sex-couple-year.html. Accessed 22 March 2020.

Jones, L., \& McCarthy, M. (2010). Mapping the landscape of gay men's football. Leisure Studies, 29(2), 161-173.

Kelleher, P. (2020). Strictly dancer who took part in history making same-sex routine shuts down 'silly' complainers. [Online] Available at: https://www.pinknews.co.uk/2020/01/03/strictlycome-dancing-same-sex-dance-dancer-shuts-down-silly-complaints/. Accessed 22 March 2020.

Kivel, B. D., Johnson, C. W., \& Scraton, S. (2009). (Re) theorizing leisure, experience and race. Journal of Leisure Research, 41(4), 473-493.

Kyriazis, S. (2020). Dancing On Ice same-sex couple: John Barrowman BLASTS haters 'You can $f^{* * *}$ right off'. [Online] Available at: https://www.express.co.uk/entertainment/music/1220275/ 
Dancing-On-Ice-same-sex-couple-John-Barrowman-judge-ITV-skater-two-men-homophobia. Accessed 22 March 2020.

Leib, A., \& Bulman, R. (2007). The choreography of gender: Masculinity, femininity, and the complex dance of identity in the Ballroom. Men and Masculinities, 11(5), 602-621.

Marion, J. S. (2008). Ballroom: Culture and costume in competitive dance. Berg.

Masters, S. (2020). Matt Evers: Dancing on Ice pro in romance admission after first dance with Ian ' $H$ ' Watkins. [Online] Available at: https://www.express.co.uk/celebrity-news/1228434/matt-eversian-h-watkins-dancing-on-ice-2020-romance-dating-partners-news. Accessed 22 March 2020.

McCormack, M. (2012). The declining significance of Homophobia: How teenage boys are redefining masculinity and heterosexuality. Oxford University Press.

McGregor, N. (2020). Dancing On Ice: First same-sex couple don't want to be 'part of a circus'. [Online] Available at: https://www.bbc.co.uk/news/newsbeat-508358040. Accessed 24 March 2020.

McMains, J. (2006). Glamour Addiction: Inside the American Ballroom Dance Industry. Wesleyan University Press.

McPhee, R. (2019). 'WHY ARE PEOPLE SCARED? IT'S 2019' Strictly star Michelle Visage demands the show introduces same-sex couples next year. [Online] Available at: https://www.thesun.co.uk/ tvandshowbiz/10118041/strictly-michelle-visage-same-sex-couples/. Accessed 22 March 2020.

Meneau, V. (2020). Coding sexual violence as love-choreographed heteronormative gender performances in Latin American competitive dancing. Journal of Gender Studies, 29(8), 962-980.

Midalia, S. (1999). Textualising Gender. Interpretations, 32(1), 27-32.

Miller, A. (2019). Dancing on Ice first same-sex couple Ian ' $H$ ' Watkins and Matt Evers struck with unique problem: 'His manhood gets in the way'. [Online] Available at: https://metro.co.uk/2019/ 12/20/dancing-ice-first-sex-couple-ian-h-watkins-matt-evers-struck-unique-problem-manhoodgets-way-11938158/. Accessed 24 March 2020.

Milton, J. (2020). Ian ' $H$ ' Watkins reveals ominous text from Strictly bosses after history-making Dancing on Ice routine. [Online] Available at: https://www.pinknews.co.uk/2020/01/20/ian-hwatkins-dancing-on-ice-strictly-come-dancing-text-the-sun/. Accessed 22 March 2020.

Miraftab, F. (2004). Invited and invented spaces of participation: Neoliberal citizenship and feminists' expanded notion of politics. Wagadu, 1(Spring), 1-7.

Morley, D. (2005). Family television: Cultural power and domestic leisure. Routledge.

Nakamura, K. and Matsuo, H. (2003). 'Female masculinity and fantasy spaces: transcending genders in the Takarazuka Theatre and Japanese popular culture' in Roberson, J. and Suzuki, N. (2003) Men and Masculinities in Contemporary Japan. London: Routledge

Nicholson, R. (2020). It's good to see queer representation on Strictly and I'm a Celebrity - but there's more to do. [Online] Available at: https://www.theguardian.com/commentisfree/2019/dec/04/queerrepresentation-strictly-im-a-celebrity-homophobia-caitlyn-jenner. Accessed 22 March 2020.

O'Connor, R. (2020). John Barrowman calls out reality TV shows for failing to include same-sex couples. [Online] Available at: https://www.independent.co.uk/arts-entertainment/tv/news/john-barrowmanreality-tv-same-sex-couples-strictly-come-dancing-on-ice-a9267946.html. Accessed 22 March 2020.

O’Neill, R. (2015). Whither critical masculinity studies? Notes on inclusive masculinity theory, postfeminism, and sexual politics. Men and Masculinities, 18(1), 100-120.

Owen, C., \& Riley, S. (2020). A poststructuralist-informed inclusive masculinity theory (PS-IMT): Developing IMT to account for complexities in masculinities, using learning to dance Latin and ballroom as an example. Journal of Gender Studies, 29(5), p533-546.

Parry, D. C., Johnson, C., \& Stewart, W. (2013). Leisure research for social justice: A response to Henderson. Leisure Sciences, 35(1), 81-87.

Peters, S. (1992). The elegant passion. Journal of Popular Culture, 25(4), 163-171.

Picart, C. J. (2002). Dancing through different worlds: An autoethnography of the interactive body and virtual emotions in ballroom dance. Qualitative Inquiry, 8(3), 348-361.

Pike, M. (2019). Dancing On Ice's Matt Evers says penises get in the way in routines with $H$ from Steps. [Online] Available at: https://www.mirror.co.uk/3am/celebrity-news/dancing-ices-mattevers-says-21132989. Accessed 22 March 2020.

Pink News (2019). Phillip Schofield is clearly thrilled that Dancing on Ice is beating Strictly to introduce the first same-sex dance couple. [Online] Accessed 22 March 2020.

Pope, H. G., Phillips, K. A., \& Olivardia, R. (2000). The Adonis complex. The Free Press.

Power, E. (2020). Dancing on Ice, episode 1 review: A ground-breaking step towards equality. [Online] Available at: https://www.telegraph.co.uk/tv/2020/01/05/dancing-ice-episode-1-reviewground-breaking-step-towards-equality/. Accessed 24 March 2020. 
Pringle, R., Kay, T., \& Jenkins, J. M. (2011). Masculinities, gender relations and leisure studies: Are we there yet? Annals of Leisure Research, 14(2-3), 107-119.

Rainbird, A. (2019). Dancing on Ice star Ian 'H' Watkins says BBC wouldn't allow him male partner on gymnastics show. [Online] Available at: https://www.mirror.co.uk/3am/celebrity-news/danci ng-ice-star-ian-h-21162463. Accessed 22 March 2020.

Richardson, N. (2018). 'Whether you are gay or straight, I don't like to see effeminate dancing': Effeminophobia in performance-level ballroom dance. Journal of Gender Studies, 27(2), 207-219.

Robinett, J. (2014). Heteronormativity in leisure research: Emancipation as social justice. Leisure Studies, 36(4), 365-378.

Robinson, S., Anderson, E., \& White, A. (2017). The bromance: Undergraduate male friendships and the expansion of contemporary homosocial boundaries. Sex Roles, 78, 94-106.

Robinson, S., White, A., \& Anderson, E. (2019). Privileging the bromance: A critical appraisal of romantic and bromantic relationships. Men and Masculinities, 22(5), 850-871.

Rusk, C. (2020). Dancing On Ice: 'The world is ready for this!' Ian 'H' Watkins and Matt Evers make history with emotional same-sex dance (and reduce John Barrowman to tears)... as Trisha Goddard takes a tumble in most dramatic launch night EVER. [Online] Available at: https://www.daily mail.co.uk/tvshowbiz/article-7854211/Dancing-Ice-Joe-Swash-reveals-nearly-took-tumble-launc hes-show.html. Accessed 22 March 2020.

Saunders, E. (2019). Strictly Come Dancing's same-sex dance got 200 complaints from homophobic viewers. [Online] Available at: https://www.mirror.co.uk/tv/tv-news/strictly-come-dancingssame-sex-20928046. Accessed 22 March 2020.

Shaw, S. M. (1994). Gender, leisure, and constraint: Towards a framework for the analysis of women's leisure. Journal of Leisure Research, 26, 8-22.

Swain, M. (2019). Strictly Come Dancing - with its first same-sex dance, is the show keeping in step with the modern dance world? [Online] Available at: https://www.telegraph.co.uk/tv/2019/11/02/ strictly-come-dancing-first-same-sex-dance-tomorrow-show-keeping/. Accessed 22 March 2020.

Telegraph. (2019). Strictly Come Dancing's Anton du Beke says he would welcome same-sex pairings. [Online] Available at: https://www.telegraph.co.uk/news/2019/11/23/strictlys-anton-du-bekesays-would-welcome-same-sex-pairings/. Accessed 22 March 2020.

Wakefield, L. (2019). Strictly's history-making same-sex dance routine sparked nearly 200 complaints because apparently we're still in the dark ages. [Online] Available at https://www.pinknews.co. uk/2019/11/21/strictly-come-dancing-same-sex-dance-complaints-bbc-johannes-radebe-grazi ano-di-prima/. Accessed 22 March 2020.

Wakefield, L. (2020). Strictly Come Dancing pro Katya Jones says she would 'love to dance with a woman'. [Online] Available at: https://www.pinknews.co.uk/2020/01/20/katya-jones-strictlycome-dancing-same-sex-routine-ed-balls-mike-bushell/. Accessed 22 March 2020.

Watts, H. (2015). Strictly Come Dancing reject CJ de Mooi claims he was SNUBBED as he wanted same sex partner. [Online] Available at: https://www.mirror.co.uk/tv/tv-news/strictly-come-danci ng-reject-cj-6384863. Accessed 22 March 2020.

Wearing, B. (1998). Leisure and feminist theory. Sage.

Williams, J. (2020). Strictly: 'There will be pressure' BBC show set for major shake-up over celeb pairings?; STRICTLY COME DANCING could be set for a major shake-up. [Online] Available at: https://www.express.co.uk/showbiz/tv-radio/1225366/strictly-come-dancing-same-sex-celeb rity-pairings-dancing-on-ice-latest-bbc-itv. Accessed 24 March 2020.

Willig, C. (2013). Introducing qualitative research in psychology. McGraw-hill education.

Wynne, A. (2019). BBC bosses 'want a drag queen to compete for the Strictly Come Dancing glitterball trophy in 2020'. [Online] Available at: https://www.dailymail.co.uk/news/article-77432 19/BBC-bosses-want-drag-queen-compete-Strictly-Come-Dancing-glitterball-trophy-2020.html. Accessed 22 March 2020.

Young, S. (2019). Strictly Come Dancing star Johannes Radebe details homophobic attack he experienced as a child. [Online] Available at: https://www.independent.co.uk/life-style/johannes-radebehomophobic-attack-strictly-come-dancing-south-africa-catherine-tyldesley-a9173916.html. Accessed 24 March 2020.

Publisher's Note Springer Nature remains neutral with regard to jurisdictional claims in published maps and institutional affiliations. 